\title{
Forced Convection Heat Rejection System for Mars Surface Applications
}

\author{
Nathan Colgan ${ }^{1}$, Gregory Nellis ${ }^{1}$, and Mark Anderson ${ }^{1}$ \\ ${ }^{1}$ UW-Madison, 1500 Engineering Drive, Madison, WI, 53706 \\ Primary Author Contact Information: 610-608-0556,ncolgan@wisc.edu
}

\begin{abstract}
A forced convection heat exchanger for waste heat rejection to the Martian atmosphere is designed based on existing heat transfer and pressure drop correlations for low-Reynolds-number finned tube arrays. The design is optimized to determine the mass-optimal heat exchanger geometry for a range of candidate heat exchanger materials and power loads. For a $100 \mathrm{~kW}$ thermal load, the optimal heat exchanger mass is found to be $27.0 \mathrm{~kg}$ and a frontal area of $3.94 \mathrm{~m}^{2}$. This is $95 \%$ less mass and area than a comparable radiator and only requires $638 \mathrm{~W}$ of fan power (or $0.6 \%$ of the output power) to operate. Optimal geometries are also found for heat rejection loads of $1 \mathrm{~kW}$ to $250 \mathrm{~kW}$ across a range of coolant and atmosphere temperatures, indicating wide applicability of this technology for Martian heat rejection applications such as cryofuel refrigeration or in-situ resource utilization (ISRU) plant cooling. An experimental facility has been designed and partially constructed to experimentally validate the predicted heat exchanger performance in a Mars-like environment. A subscale heat exchanger has been built based on the predicted mass-optimal geometry. Heat transfer and pressure drop performance data of this heat exchanger will be collected and will refine the modelling predictions.
\end{abstract}

\section{INTRODUCTION}

Future crewed Mars surface missions will require numerous high-power technologies, including fission surface power systems, in-situ resource utilization (ISRU) plants for generating rocket propellant and other consumables, cryofuel refrigeration, and habitat thermal management, ranging from 10's to 100's of kW[1]. Radiative heat rejection systems have a long flight heritage and are compatible with both space and Mars surface environments. However, radiative heat transfer provides relatively poor heat transfer rates except at very high absolute temperature which leads to massive heat rejection systems and a relatively high mass-optimal cycle heat rejection temperature when coupled to a fission power system, reducing the cycle thermal efficiency. For example, Sondelski[2] performed a mass optimization on a supercritical $\mathrm{CO}_{2}\left(\mathrm{sCO}_{2}\right)$ recuperated Brayton cycle reactor system designed to generate $40 \mathrm{kWe}$ on the Martian surface. She found that the radiator accounted for the majority of the total system mass, $570 \mathrm{~kg}$ out of $782 \mathrm{~kg}$. The high radiator mass tended to push the compressor inlet temperature away from the vapor dome, the region on a phase diagram representing saturation, resulting in a substantial reduction in the fluid density entering the compressor which negated the primary benefit of using supercritical power cycles. As a result, the cycle efficiency was only $27 \%$ and required an $84.4 \mathrm{~m}^{2}$ radiator. For a cryofuel refrigeration application, high heat rejection temperature significantly reduces efficiency as well due to the increased required refrigerant compression.

Using a forced-convection heat exchanger to transfer waste heat to the Martian atmosphere may improve performance compared to a radiator. Convection offers much higher effective heat transfer coefficients than radiation and a weaker dependence on temperature, allowing the power 
block to operate at lower heat rejection temperatures. This is particularly important for $\mathrm{sCO}_{2}$ cycles that need to operate near the vapor dome. Convection heat transfer surfaces do not need to be exposed to the sky, allowing for a much more compact structure and eliminating the need for the complex deployment mechanisms required by a large radiator due to launch vehicle limitations. If a convective heat exchanger that transfers waste heat to the atmosphere without significant parasitic power loss and that is less massive than a similarly-performing radiator can be realized, such a system would provide substantial mass, cost, and complexity savings to a future Mars surface mission.

\section{MODELING}

The Martian atmosphere is a challenging heat transfer medium, consisting of predominately $\mathrm{CO}_{2}$ at an average pressure and temperature of $600 \mathrm{~Pa}$ and $220 \mathrm{~K}$ [3]. This low-density environment drastically reduces the forced convection heat transfer coefficient at a given flow rate due to the lower Reynolds number, requiring a high volumetric flow rate through the heat exchanger causing a relatively large pressure loss, while the achievable pressure rise of an axial fan also decreases at low air density in accordance with the classical fan scaling laws. To determine if these conditions are suitable for convective waste heat rejection, a numerical model of a plane-finned staggeredtube crossflow heat exchanger with a pitch-diameter ratio of 2 is developed and is discussed in detail in Colgan et al.[4] This heat exchanger architecture was chosen because it offers both low pressure loss and high conductance. Based on an input set of heat rejection parameters and heat exchanger geometry, the model determines the gas flow velocity corresponding to the required heat transfer coefficient using the effectiveness-NTU method. A fan power mass penalty that accounts for the mass of the fan, motor, and the increased reactor mass required to supply this power is calculated based on the required flow velocity and frontal area. Additionally, a mass penalty is assessed based on the $\mathrm{sCO}_{2}$ pressure drop within the heat exchanger.

The mass-optimal heat exchanger geometry for any given set of heat rejection parameters, atmospheric conditions, and choice of high-pressure side fluid and tube material was then determined via a two-step optimization algorithm. Tube and fin size constraints are determined by commercial availability while tube length and overall height, which in combination with the tube pitch and diameter limits the number of tubes per row, are limited to $4 \mathrm{~m}$ to fit within a typical launch fairing. The number of tube rows is limited to 10 by the lack of availability of a pressure drop correlation above this number. The relation between heat exchanger mass and these parameters is highly non-linear and non-differentiable so a mixed-integer non-linear (MINLP) solver is used for optimization. The optimization process is broken into two steps. First, a solver is implemented that optimizes the continuous variables for fixed values of the discrete variables using a freely-available global non-linear optimizer[5]. The discrete solver to determine the optimal number of tube rows and tubes per row uses the first order two-dimensional gradient descent method. The optimal mass is convex across the whole search area so the gradient descent method is able to consistently find the global minimum regardless of the initial guess values. 


\section{RESULTS}

The optimal geometry and mass for steel heat exchangers of various sizes, at an atmospheric temperature of $220 \mathrm{~K}$ and pressure of $600 \mathrm{~Pa}$ and coolant pressure of $9 \mathrm{MPa}$ are given in the first 4 columns of Table 1. For each power level studied, the optimal fin pitch equaled the tube length, i.e. the optimal geometry was a bare tube array. The increase in the heat transfer from the fins did not outweigh the associated mass and pressure drop increase at any fin density. This behavior is noticeably different than typical heat exchanger design in standard atmospheric conditions, stemming from the fins' lower heat transfer coefficient in the low-Reynolds-number flow and the optimization for mass instead of volume. To confirm this observation, the optimal $400 \mathrm{~kW}$ heat exchanger geometry in $100 \mathrm{kPaCO}$ is determined while limiting the length and height to $1 \mathrm{~m}$. The optimal geometry for this case is shown in the last column of Table 1; notice that the heat exchanger has a fin pitch of $1.294 \mathrm{~mm}$ corresponding to a typical finned-tube design. Additionally, the Mars-optimal heat exchangers had much smaller tube diameters than the Earth-optimal geometry, likely due to the greater required surface area caused by the lower heat transfer coefficient. The small tube diameter and low gas pressure result in a Knudsen number, defined as the ratio of the molecular mean free path and the geometrical length scale and equal to:

$$
K n=\frac{\mu}{\rho L} \sqrt{\frac{\pi M}{2 k_{B} T}}
$$

where $\mu$ is the dynamic viscosity, $\rho$ is the fluid density, $L$ is the length scale, $M$ is the molecular mass of the fluid, and $k_{B}$ is the Boltzmann constant for the Mars-optimal heat exchangers of approximately 0.01 , indicating that the flow is on the border between continuum and slip flow, while the tube arrays used to generate the correlations used to predict pressure drop were firmly in the continuum regime[6]. This difference may reduce the accuracy of the predicted results, increasing the value of experimental data in this regime.

By determining the optimal cycle mass, fan power, and pressure drop for a range of input conditions, correlations were developed to integrate the heat exchanger model into Sondelski's model of a Mars fission power system thermal cycle in place of the radiator to determine how this change affects the optimal overall cycle mass and performance. The use of a forced-convection heat exchanger reduced the predicted optimal cycle mass for a $40 \mathrm{kWe}$ power system by $80 \%$, from $782 \mathrm{~kg}$ to $159 \mathrm{~kg}$. Table 2 compares the two cycles. The heat exchanger cycle has a $42 \mathrm{~K}$ lower minimum cycle temperature, increasing thermal efficiency from $27 \%$ to $36 \%$. The heat exchanger masses significantly less than the radiator, and the frontal area of the heat exchanger is 94\% less than the required radiator surface area, eliminating the need for complex deployment mechanisms. The required fan power in this case is approximately $1 \mathrm{kWe}$ and the atmosphere-side pressure loss is approximately $12 \mathrm{~Pa}$.

Figure 1 shows the dependence of the optimal cycle mass on the rate of heat rejection from 40 to $120 \mathrm{~kW}$ using Stainless Steel, Aluminum, Inconel, Titanium, and Copper tubes. Aluminum provided the lowest mass in each case. 
Table 1: Optimal stainless steel heat exchanger geometry examples

\begin{tabular}{|c|c|c|c|c|c|}
\multicolumn{7}{|c|}{ Parameter } & \multicolumn{7}{|c|}{ Value } \\
\hline $\begin{array}{c}\text { Atmospheric } \\
\text { Pressure [kPa] }\end{array}$ & 0.6 & 0.6 & 0.6 & 0.6 & 100 \\
\hline Heat Load [kW] & 1 & 10 & 100 & 250 & 400 \\
\hline Inlet Temp, [K] & 400 & 400 & 400 & 400 & 400 \\
\hline Outlet Temp, [K] & 350 & 350 & 350 & 350 & 350 \\
\hline Length, [mm] & 102 & 330 & 1647 & 3933 & 1000 \\
\hline Tube rows & 1214 & 2455 & 2974 & 1827 & 57 \\
\hline Tube Diam [mm] & 0.5 & 0.5 & 0.672 & 1.074 & 8.729 \\
\hline Height, [mm] & 1214 & 2455 & 4000 & 3925 & 1000 \\
\hline Depth, [mm] & 2 & 2 & 2.7 & 6.5 & 34.9 \\
\hline Tube columns & 2 & 2 & 2 & 3 & 2 \\
\hline Fin Pitch, [mm] & 102 & 330 & 1647 & 3933 & 1.294 \\
\hline Fan Power, [W] & 6.4 & 82.9 & 1387.5 & 4510 & 8675 \\
\hline Optimal Mass, [kg] & 0.516 & 3.673 & 36.2 & 100.4 & 78.52 \\
\hline
\end{tabular}

Table 2: Comparison of optimal thermal cycles for a $40 \mathrm{kWe}$ power system

\begin{tabular}{|l|r|r|}
\hline Performance Parameter & Radiator & Air cooling HX \\
\hline Mass Flow Rate [kg/s] & 1.14 & 0.664 \\
\hline Heat Rejection Temperature [K] & 404 & 361.8 \\
\hline Minimum Cycle Temperature [K] & 414 & 329 \\
\hline Maximum Cycle Temperature [K] & 900 & 900 \\
\hline Cycle Efficiency & 0.27 & 0.361 \\
\hline Recuperator Mass [kg] & 111 & 29.8 \\
\hline Heat Rejection Mass [kg] & 570 & 26.8 \\
\hline Reactor Mass [kg] & 101 & 102.5 \\
\hline Combined Mass [kg] & 782 & 159 \\
\hline Area, [m²] & 84 & 5.29 (frontal area) \\
\hline
\end{tabular}

The performance of the optimal heat exchanger geometry was investigated while varying atmospheric conditions to ensure that sufficient heat rejection could be achieved in any realistic ambient conditions likely to be encountered at proposed human Mars mission landing sites. Pressure was varied from 500 to $900 \mathrm{~Pa}$ and temperature from 220 to $280 \mathrm{~K}$, based on weather data from the Viking 2 lander but at $200 \mathrm{~Pa}$ lower pressures to investigate the upper range of landing elevation[7]. As the geometry is fixed, increased fan power is required to meet the required heat rejection loads at lower pressures and higher temperatures due to the lower atmospheric density. Figure 2 shows the variation of required fan power with atmospheric conditions. As the highest temperatures occurred in summer and the highest pressures in winter, the highest-power points are not considered realistic and so the heat exchanger is predicted to require at most approximately $4 \mathrm{kWe}$ to operate in the most adverse conditions, or $10 \%$ of the cycle output power. 


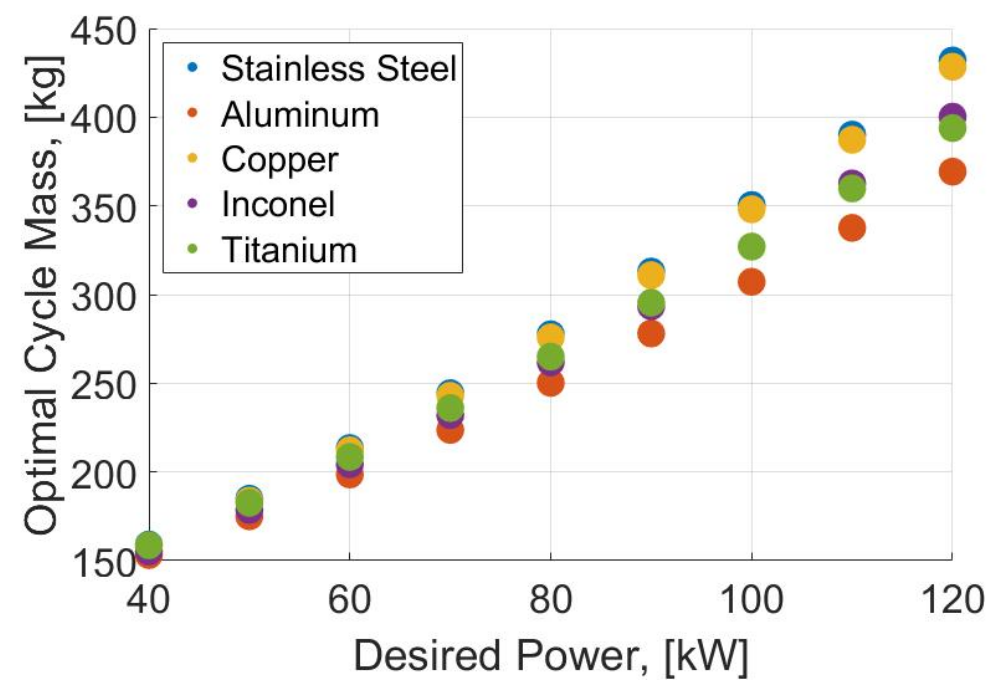

Fig. 1. Optimal heat exchanger mass vs heat rejection rate. The coolant is $\mathrm{SCO}_{2}$ at an inlet temperature of $400 \mathrm{~K}$ and outlet temperature of $350 \mathrm{~K}$.

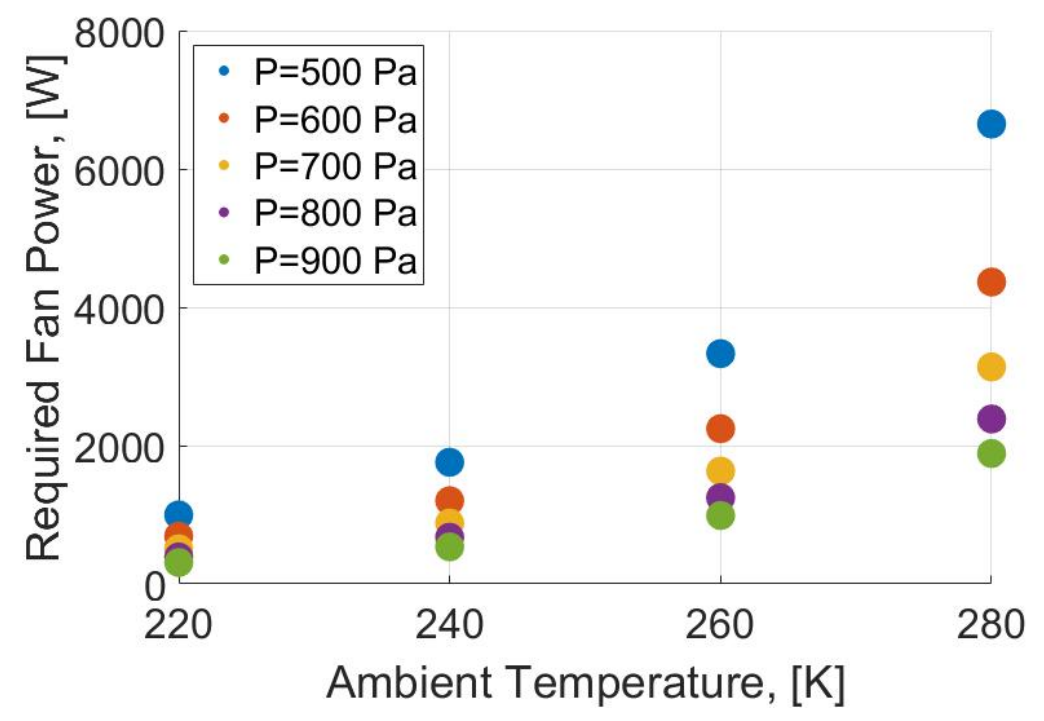

Fig. 2. Optimal $40 \mathrm{kWe}$ heat exchanger mass vs ambient pressure for a range of ambient pressures. Other parameters are the same as shown in Table 2.

Overall, the modelling suggests that a forced-convection heat exchanger is capable of fulfilling the waste heat rejection requirements of a fission power system at a range of electrical power levels and in the entire range of foreseeable landing site ambient conditions, while weighing significantly less and requiring less space than a radiator and increasing cycle efficiency. 


\section{EXPERIMENTAL VALIDATION}

\subsection{Experimental Facility}

The predicted performance is based on gas side correlations that have not been tested under conditions that are directly relevant to the Martian atmosphere. Specifically, there is no experimental validation in the literature for any heat transfer coefficient or pressure drop for compact heat exchangers in such a rarefied environment where the Knudsen number is near the transition to slip flow. Additionally, simplifying assumptions made in the model, such as assuming uniform axial flow through the heat exchanger, may have skewed the model predictions. In order to validate the results, an experimental facility is being constructed to test heat exchanger performance in a Mars-like environment. The facility consists of a $0.75 \mathrm{~m}^{3}$ vacuum chamber in the UW-Madison Thermal Hydraulics Lab. The vacuum chamber, shown in Figure 3, has a large door at one end allowing for easy access to the test section, numerous feedthroughs for data, gas lines, and power cables, and two large windows for observation. Before conducting the heat exchanger tests, a vacuum pump removes the air from the chamber and industrial grade $(99 \%) \mathrm{CO}_{2}$ is introduced until the chamber pressure reaches $800 \mathrm{~Pa}$. As the test are performed at room temperature, the higher pressure is required to match the average Mars atmospheric density. The pressure is monitored with a piezoelectric vacuum gauge.

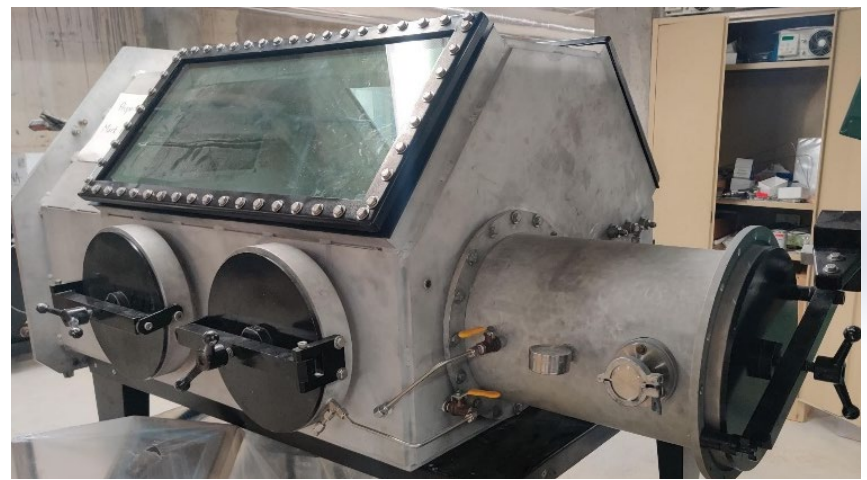

(a)

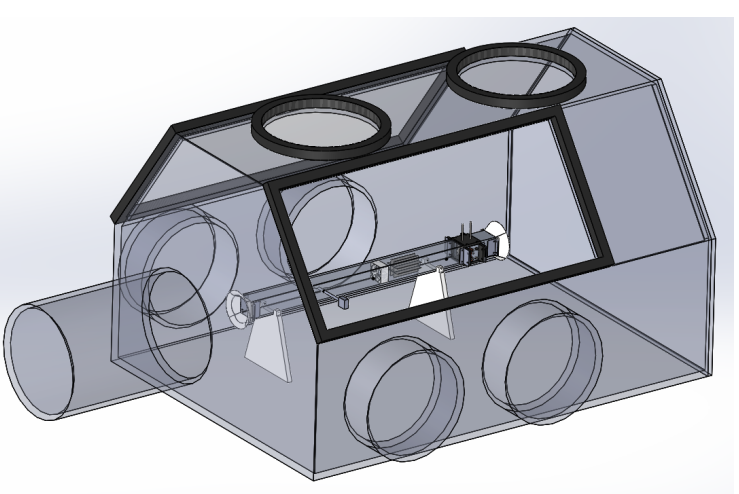

(b)

Fig 3: A) Photograph of the experimental facility. B) Render of the facility and the test section

\subsection{Test Section}

The experimental test section is essentially an open cycle wind tunnel placed within the vacuum chamber. A diagram of the test section is shown in Figure 4 and a photograph of the completed test section body and heat exchanger frame are shown in Figure 5. Gas flows through the test section from right to left. The body of the test section consists of a 1.75" square Aluminum tube. This size was determined to maximize the heat exchanger frontal area while maintaining a sufficient number of hydraulic diameters to minimize flow non-uniformity. A 3D-printed flared inlet section reduces pressure loss and flow non-uniformity. 


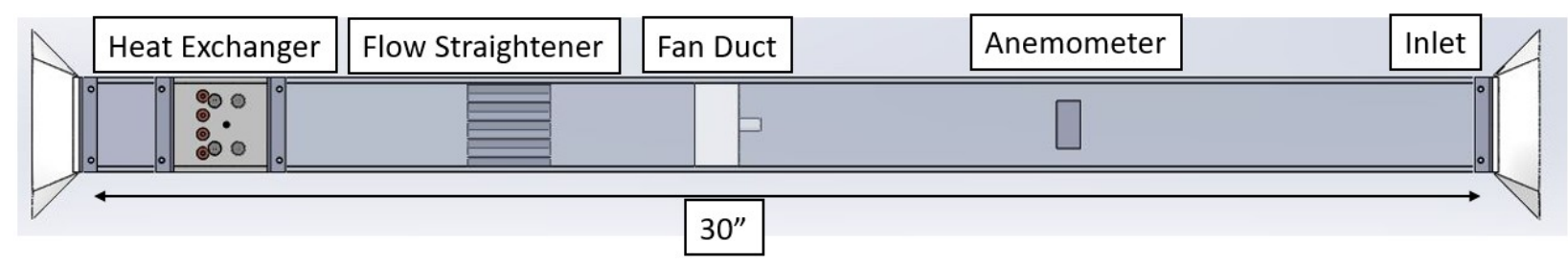

Fig. 4: Diagram of the test section

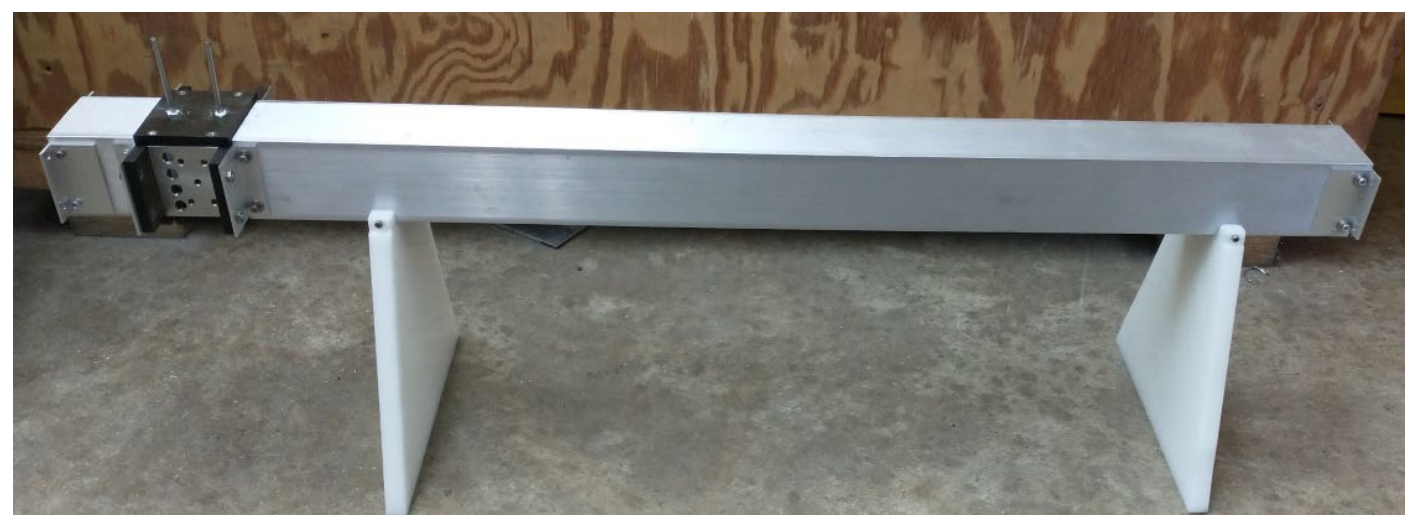

Fig. 5: Photograph of the completed test section body and heat exchanger frame.

\subsubsection{Flow Measurement}

A hot-film anemometer, positioned 5 hydraulic diameters downstream of the inlet to reduce measurement error, measures the gas flow rate through the test section. A hot-film anemometer is chosen to measure flow rate as it induces very little pressure drop in the flow. Overall achievable pressure drop is a major limiting factor in the design of the test section due to the low gas density and fan blade Reynolds number, defined as

$$
R e_{b}=\frac{\rho U_{m i d} c_{m i d}}{\mu}
$$

where $U_{\text {mid }}$ is the linear blade speed at the midspan and $c_{\text {mid }}$ is the chord at the midspan, significantly reducing fan pressure rise and efficiency. The anemometer has been calibrated to work at the Reynolds numbers relevant to the test conditions but in air at 1 bar, therefore calibration of the anemometer in the test conditions will be performed prior to data collection by flowing $\mathrm{CO}_{2}$ from a high-pressure source through a thermal mass flow meter, through a needle valve, into the experimental facility at $800 \mathrm{~Pa}$ and through the test section to obtain known flowrates to compare the anemometer data to.

\subsubsection{Fan Selection}

Proper fan selection for this project was challenging due to the limited data available on fan performance in relevant conditions. According to the classical fan scaling laws, pressure rise increases with fluid density and with the square of rotational speed and fan diameter, therefore in order to generate sufficient pressure rise in the low-density fluid, rotational speed should be as 
high as possible for a given fan size and airfoil shape. However, the speed of sound on Mars is lower than on Earth, approximately $270 \mathrm{~m} / \mathrm{s}$, and compressibility effects have been found to significantly erode fan efficiency at high tip Mach numbers[8], limiting the maximum feasible fan speed and therefore blade Reynolds number, although pressure rise has not been shown to be strongly affected. Finally, tests on fan performance at low blade Reynolds number have shown that below a value of roughly 20000 , the fan scaling laws overpredict pressure rise by as much as $25 \%[9]$. For the operational heat exchanger, assuming a fan diameter equal to the tube length of 1 $\mathrm{m}$, a tip Mach number of 0.4, and a mid-span chord equal to the blade length, the blade Reynolds number would be approximately 23000 so the typical fan scaling laws should still apply albeit at reduced efficiency. Employing the correlations developed by Quin et al.[9] for fan performance at low Reynolds number for the fan blade design used in the Papst 4184NGX axial fan, a single ducted fan of this design should produce $37 \mathrm{~Pa}$ of pressure rise at a flow speed of $12 \mathrm{~m} / \mathrm{s}$ through the heat exchanger, and Neustein et al. [10] predict an efficiency of approximately 0.45 at this Reynolds number and flow coefficient, defined as

$$
\phi=\frac{\dot{V}}{U_{\text {mid }} A_{\text {fan }}}
$$

where $\dot{V}$ is the volumetric flowrate and $A_{f a n}$ is the fan frontal area, indicating that fan performance should be sufficient to meet the flow requirements of the optimal heat exchanger geometry.

However, due to its much smaller radius, fan performance in the experimental test section may vary considerably from that expected by simply applying the fan scaling laws as the fan will operate in an unusual low ( 1000-2000) Reynolds number, high Mach number regime, for which scarce experimental data exists. This unavoidable discrepancy between the flow regimes of the experimental and operational fans precludes the possibility of collecting relevant fan performance data, but also allows for more relaxed experimental fan selection criteria as the only requirement is that it be able to generate sufficient flow rate and pressure rise to match that required by the optimal heat exchanger design of $12 \mathrm{~Pa}$ at $12 \mathrm{~m} / \mathrm{s}$. Veisman et al.[11] describe the construction of a low-density multi-fan wind tunnel for testing the Mars Ingenuity helicopter using an array of offthe-shelf Delta Electronics GFM0812DUB7S contra-rotating axial fans. They report a decrease of the head coefficient, defined as

$$
\psi=\frac{\Delta P}{\rho U_{m i d}^{2}}
$$

where $\Delta P$ is the fan pressure rise, of $40 \%$ at test conditions compared to STP conditions. Based on the manufacturer-provided $\Delta P-\dot{V}$ curve for this fan, the estimated pressure rise at the desired flow rate in test conditions is $13 \mathrm{~Pa}$. If more pressure rise is required to overcome losses in the test section, a second fan can be added in series to raise the pressure. Veisman et al. also report that the fans operated well in the low-pressure environment although they note the fans began to overheat after $10 \mathrm{~min}$ of operation due to decreased convective cooling of the surrounding fluid. 
This model fan will be used for this project as it is the only fan of appropriate size and cost demonstrated to operate at the test conditions. Power and data for the fan will be fed through a small hole in the test section wall upstream of the fan and through a vacuum feedthrough to a power supply and data acquisition system. A thermocouple will be placed on the fan to monitor fan motor temperature.

In an actual waste heat rejection heat exchanger on Mars, the fan would likely be mounted directly upstream of the tube array to minimize overall size and system mass, however the model assumed uniform axial flow so to test the modelling results as accurately as possible, this flow condition is desired for the experimental validation. A further round of tests measuring heat exchanger performance when the fan is moved directly upstream of the heat exchanger is planned to determine the effect of flow vorticity on the performance. The fan is placed upstream of the heat exchanger instead of downstream because the gas downstream is predicted to be nearly $150 \mathrm{~K}$ hotter than the inlet temperature during operation, further reducing fan performance by lowering the density and also possibly overheating the fan motor.

\subsubsection{Flow Straightener}

A flow straightener consisting of bundle of small tubes reduces flow vorticity downstream of the fan. Tube bundles are an effective, low-pressure-drop, and low-cost method of reducing vorticity. The tube length to diameter ratio is 6 , a value typically used in wind tunnel flow straighteners to significantly reduce vorticity[12].

\subsubsection{Heat Exchanger Frame}

The heat exchanger frame holds the test heat exchanger in place and provides pressure taps to measure the pressure drop across the heat exchanger. The frame is primarily built from MICA sheet to provide electrical insulation between the heat exchanger and the test section. The ends of the frame are machined from Aluminum due to the complex geometries required and because these faces do not require electrical insulation as they are only in contact with the heat exchanger. On one side, through-holes in the end face allow machine screws to fix the heat exchanger header in place while on the other end, to allow for thermal expansion of the heat exchanger tubes, threaded rods fixed to the header pass through the end plate and nuts on these rods compress springs against the end face to provide tension to the heat exchanger so that the tubes remain straight during heating. This sprung face is shown in Figure 6 below.

Copper standoffs also pass through the end faces of the frame to supply electrical power to the heat exchanger. Pressure taps are located immediately upstream and downstream of the heat exchanger to measure the pressure drop. Flexible hoses attached to the pressure taps will be passed through vacuum feedthrough to a low-range, vacuum-compatible differential pressure sensor with a resolution of $0.056 \mathrm{~Pa}$. Thermocouples to measure the inlet and outlet $\mathrm{CO}_{2}$ temperature will also be added. 


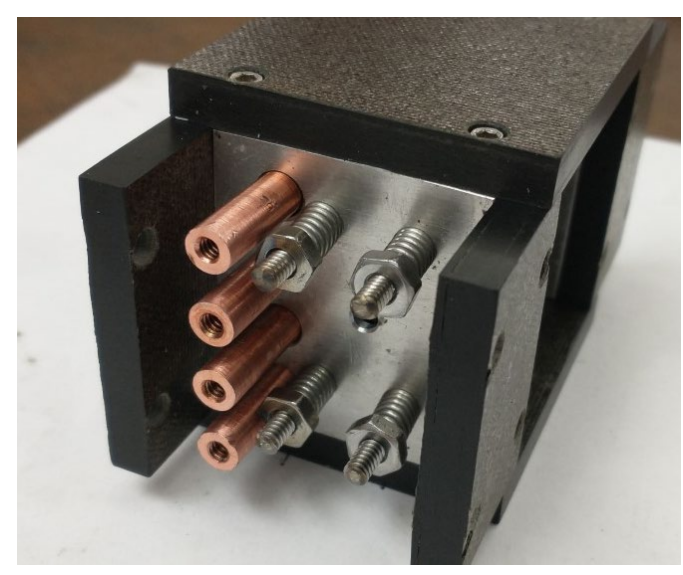

Fig. 6: Heat exchanger frame showing the sprung mounts and Copper standoffs. Note that this photograph was taken before the installation of the pressure taps.

\subsection{Experimental Heat Exchanger}

To accurately reflect the behavior of the optimal heat exchanger design discussed above while allowing for testing within the test section, an experimental heat exchanger was constructed to the same geometrical parameters as a 1.75 " $\times 1.75$ " subsection of the optimal design. The heat exchanger consists of 2 rows of 430.02 " diameter 304 Stainless Steel tubes arranged in a staggered array with a pitch of 0.04 ". To investigate the effect of tube diameter and Knudsen number on performance, a second heat exchanger consisting of 0.042 " diameter tubes will also be built. The primary difference between the experimental and modelled heat exchangers is that the experimental heat exchanger will be heated via electrical resistance to obviate the need for a complex fluid heating and pumping system in the vacuum chamber and to allow for easier temperature measurement in the tubes without disturbing the gas flow. Given the tube wall thickness of 0.002 " and the known bulk resistivity of stainless steel, the resistance of the tube array and thus the required current to generate $26.5 \mathrm{~W}$, the power required to match the heat flux of the optimal heat exchanger, are

$$
\begin{gathered}
\mathrm{R}=\frac{\rho L_{\text {tube }}}{\pi N_{\text {tube }} t_{\text {wall }}\left(d_{\text {tube }}-t_{\text {wall }}\right)}=0.0048 \Omega \\
I=\sqrt{\frac{Q}{R}}=74.3 \mathrm{~A}
\end{gathered}
$$

where $L_{\text {tube }}$ is the tube length, $N_{\text {tube }}$ is the number of tubes, $t_{\text {wall }}$ is the wall thickness, $d_{\text {tube }}$ is the tube outer diameter, and $Q$ is the required heating power. The tubes were cut to length on a diamond saw and deburred with 320 grit abrasive paper. The headers were machined from 303 Stainless Steel plate. This alloy is more easily machinable than other forms of Stainless while retaining its physical, electrical, and thermal properties and allowing for easier electrical bonding with the Stainless Steel tubes. The headers consisted of 1/8" thick plates, milled down to 1/16" 
where the tubes are located. The machining and assembly process is shown in Figure 7. For each tube, a 0.021" diameter hole was drilled into the header using a microdrill and microscope (Figure 7A-B). Threaded holes were drilled to attach the Copper standoffs and threaded rods to the headers as described above. To assemble the heat exchanger, the headers were fixed to a jig and the tubes were inserted through the corresponding holes (7C-D). The tubes will then be bonded to the headers in a way that minimizes electrical resistance to avoid excess heat generation in the headers, resulting in a completed heat exchanger $(7 \mathrm{E}$, although the bonding attempt used before this picture was taken was unsuccessful). Thin-gauge thermocouple wire will be threaded through one or more of the tubes in each row to measure the wall temperature. The resistive heating method will also result in a nearly axially-constant tube temperature due to the slender geometry, reducing measurement uncertainty stemming from thermocouple placement.

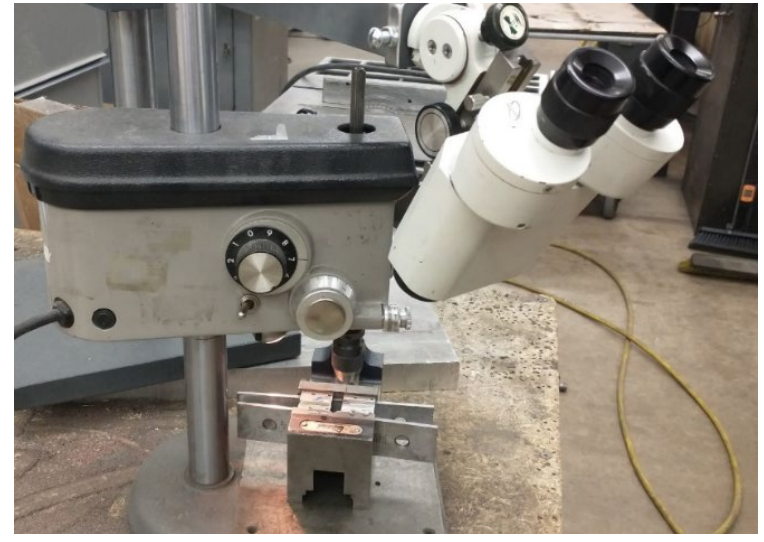

(a)

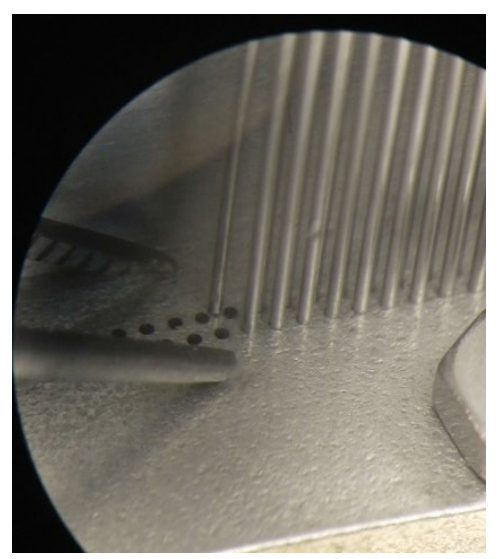

(c)

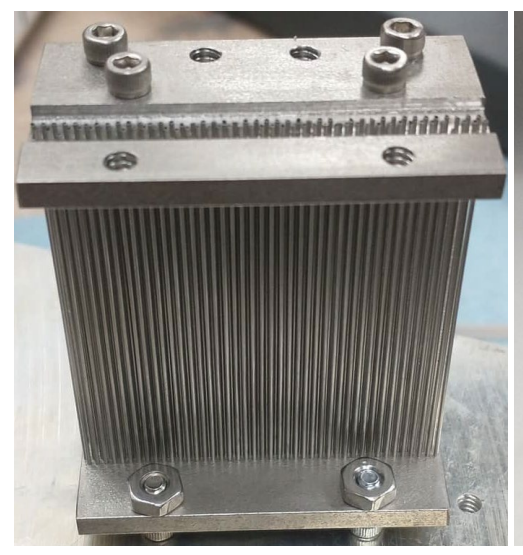

(d)

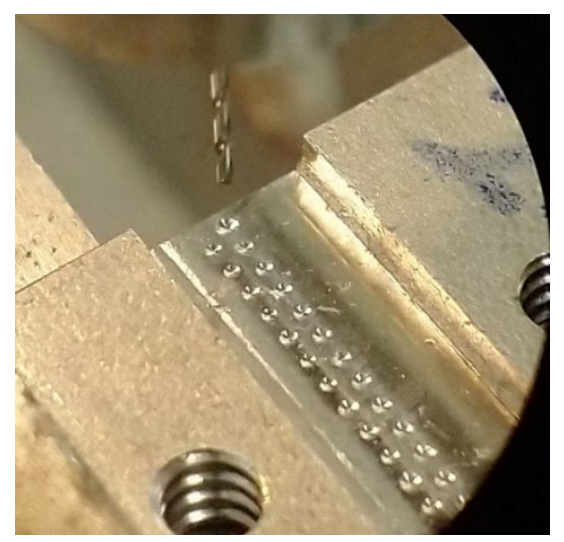

(b)

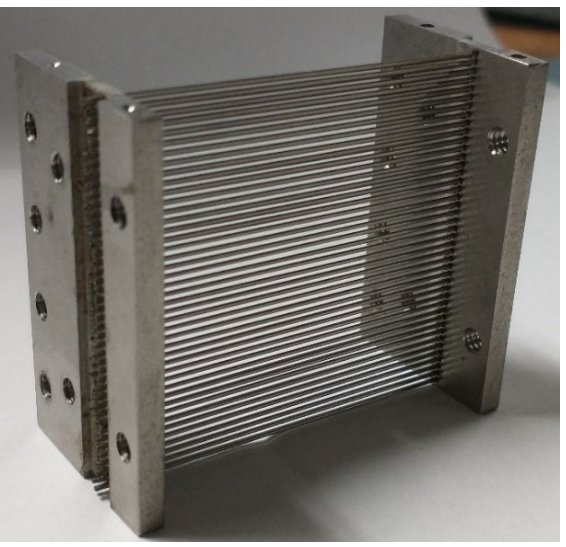

(e)

Fig 7: A) Microdilling setup. B) View through microscope of the hole drilling. C) Tubes are inserted into holes by hand using tweezers. D) The heat exchanger with all tubes inserted. E) The heat exchanger following tube bonding and jig removal.

By measuring the tube surface, $\mathrm{CO}_{2}$ inlet and outlet temperatures, the conductance of heat exchanger can be calculated from the effectiveness and compared the predicted values from the model for a range of electrical power levels and fan speeds. Similarly, the pressure drop will be 
measured at a range of fan speeds and compared to the values predicted by the model. These tests will be repeated for at least two heat exchanger geometries to investigate the effect of Knudsen number on performance and with both uniform axial flow and with the fan immediately upstream of the heat exchanger to examine the effects of flow vorticity.

\section{CONCLUSION}

Overall, the predicted heat exchanger performance across all conditions and applications compares extremely favorably in Martian conditions to current radiator-based heat rejection systems and suggests that this technology could be beneficial to any future Mars missions. Heat exchangers up to $250 \mathrm{~kW}$ are compact enough to deploy to the Martian surface using current launch vehicles without requiring in-situ deployment mechanisms. In all cases under Mars conditions the optimal heat exchanger geometry contained no fins and consisted of a large number of very small tubes. The heat exchanger geometry optimized for average Mars surface conditions is predicted to adequately transfer waste heat to the environment with only a modest increase in fan power across a wide range of possible Mars ambient conditions. A fan optimized to deliver the required gas flow through the optimal heat exchanger should follow the classical fan scaling laws, albeit at an efficiency of $45 \%$. Work is progressing to experimentally validate these modelling predictions. The experimental data will be used to refine the modelling assumptions as well as collect novel data on tube array heat exchanger performance at high Knudsen numbers.

\section{FUTURE WORK}

Future work on this project includes completing the experimental facility and hardware fabrication, sensor calibration, and data collection. Principally, an adequate method of electrically bonding the heat exchanger tubes to the headers must be determined and implemented, the 3D-printed inlet, outlet, and fan shroud must be printed, and the flow straightener must be assembled. Once these components are assembled, the system can be integrated into the experimental facility and powered on. Hot-wire anemometer will be calibrated, and a velocity profile across the channel may be recorded to understand the flow conditioning. Data will then be recorded for a variety of heat fluxes and flowrates, for heat exchangers of varying Knudsen number, and for varying fan position. This data will refine the assumptions used in the model so that the model more accurately predicts system performance.

\section{REFERENCES}

1. NASA-SP-2009-566, Human Exploration of Mars Design Reference Architecture (DRA) 5.0, National Aeronautics and Space Administration, Washington, D.C. (2009).

2. B. SONDELSKI, Mass Optimization of a Supercritical $\mathrm{CO}_{2}$ Brayton Cycle with a Direct Cooled Nuclear Reactor for Space Surface Power. Master's Thesis, University of Wisconsin, Madison, (2019)

3. R.M. HABERLE, "Solar System/Sun, Atmospheres, Evolution of Atmospheres Planetary Atmospheres: Mars", Encyclopedia of Atmospheric Sciences, (2015) 
4. N. COLGAN, G. NELliS, M. ANDERSON, "Mass Optimization of a Convective Heat Exchanger for Mars Surface Reactor Waste Heat Rejection", Nuclear and Emerging Technologies for Space, Track 2: Nuclear Fission Power and Propulsion (pp. 20-24). American Nuclear Society, (2021)

5. R. FELDT. BlackBoxOptim.jl, (2019), Github Repository, https://github.com/robertfeldt/BlackBoxOptim.j1

6. Heat Exchanger Design Handbook (1983) Vol. 1, Hemisphere, New York, (1983)

7. G. MARTINEZ et al., "The Modern Near-Surface Martian Climate: A Review of In-situ Meteorological Data from Viking to Curiosity", Space Sci Rev (2017) 212:295-338

8. M. ANYOJI, D. NUMATA, H. NAGAI, K. ASAI, "Effects of Mach Number and Specific Heat Ratio on Low-Reynolds-Number Airfoil Flows," AIAA Journal, vol. 53, no. 6, pp. 16401654, Oct. 2014.

9. D. QUIN, R. GRIMES, "The Effect of Reynolds Number on Microaxial Flow Fan Performance", Journal of Fluids Engineering, (2008)

10. J. NEUSTEIN, "Low Reynolds Number Experiments in an Axial Flow Turbomachine," ASME J. Eng. Power, pp. 257-295. (1964)

11. M. VEISMAN, C. DOUGHERTY, J. RABINOVITCH, A. QUON, M. GHARIB, "Low-Density Multi-Fan Wind Tunnel Design and Testing for the Ingenuity Mars Helicopter", Experiments in Fluids, (2021)

12. J. BARLOW, W. RAE, A. POPE, Low-Speed Wind Tunnel Testing, $3^{\text {rd }}$ ed., John Wiley and Sons, (1999) 